This is the peer reviewed version of the following article:

Hobday, M. and Chikritzhs, T. and Liang, W. and Meuleners, L. 2015. The effect of alcohol outlets, sales and trading hours on alcohol-related injuries presenting at emergency departments in Perth, Australia, from 2002 to 2010. Addiction. 110 (12): pp. 1901-1909

which has been published in final form at http://doi.org/10.1111/add.13063

This article may be used for non-commercial purposes in accordance with Wiley Terms and Conditions for Self-Archiving at http://olabout.wiley.com/WileyCDA/Section/id-820227.html\#terms 
The effect of alcohol outlets, sales and trading hours on alcohol-related injuries presenting at Emergency Departments in Perth, Australia, from 2002 to 2010

Michelle Hobday (corresponding author)

$\mathrm{PhD}$, Research Fellow

National Drug Research Institute

Health Research Campus

Curtin University

GPO Box U1987

Perth WA 6845

michelle.hobday@curtin.edu.au

Tel: +61 892663552

Fax: +61 892661611

\section{Tanya Chikritzhs}

$\mathrm{PhD}$, Professor

National Drug Research Institute

Health Research Campus

Curtin University

GPO Box U1987

Perth WA 6845

t.n.chikritzhs@curtin.edu.au

\section{Wenbin Liang}

$\mathrm{PhD}$, Research Fellow

National Drug Research Institute

Health Research Campus 
Curtin University

GPO Box U1987

Perth WA 6845

w.liang@curtin.edu.au

\section{Lynn Meuleners}

PhD, Professor

Curtin-Monash Accident Research Centre

Faculty of Health Sciences

Curtin University

GPO Box U1987

Perth WA 6845

1.meuleners@curtin.edu.au

Running Head: Effect of alcohol outlets, sales and hours

Word count: 3,587

Declaration of interest: None 


\begin{abstract}
Background and aims: Few studies have investigated the combined effects of alcohol sales, outlet numbers and trading hours on alcohol-related harms. This study aimed to test whether associations: (i) exist between alcohol-related Emergency Department (ED) injuries and alcohol sales and counts of outlets; (ii) vary between on- and off-premises outlets; and (iii) vary by trading hours conditions (extended trading permits (ETP) vs. standard hours).
\end{abstract}

Design: Panel study using 117 postcodes over 8 years (2002-2010): 936 data points.

Setting: Perth, Australia.

Participants: ED injury presentations, aggregated to postcode-level.

Measurements: Alcohol-related injuries were identified using time-based surrogate measures: Night injuries $(n=51,241)$ and Weekend night injuries $(n=30,682)$. Measures of alcohol availability included number of outlets with standard and extended trading hours, and mean sales per postcode. Negative binomial regression modelling with random effects was used to examine associations between availability and alcohol-related injury, controlling for socio-demographic characteristics.

Findings: (i) Night injuries were significantly associated with counts of on-premises outlets (IRR: 1.046; 95\% CI: 1.014-1.078) and sales per off-premises outlet (IRR: 1.019; 95\% CI: 1.004-1.035); (ii) Counts of on-premises outlets were positively associated with alcoholrelated injury while counts of off-premises outlets indicated a negative association; and (iii) Weekend night injuries increased by about $5 \%$ per on-premises outlet with an ETP (IRR: $1.049 ; 95 \%$ CI: $1.015-1.084)$ and by less than $1 \%$ for outlets with standard trading hours (IRR: 1.008; 95\% CI: 1.004-1.013).

Conclusions: Regions of Perth, Australia with greater off-premises alcohol sales and counts of on-premises alcohol outlets, particularly those with extended trading hours, appear to have higher levels of alcohol-related injuries. 


\section{Introduction}

A large body of research has linked the consumption of alcohol with increased risk of injury $(1,2)$. International research has demonstrated the association between alcohol availability and harms including assault $(3,4)$, domestic violence $(5,6)$, road crashes $(7,8)$, child maltreatment $(9)$ and problem drinking $(10,11)$. Three readily quantifiable indicators of alcohol availability are the number of licensed outlets, trading hours and volume of alcohol sales. Each of these indicators has been demonstrated to be associated with alcohol-related harm; however, they have rarely been combined in a single model allowing their independent effects on alcohol-related harms to be investigated.

The number of outlets in a defined area can be measured using absolute counts of outlets, or alcohol outlet density - defined as outlet counts per population, geographical area or roadway length. Research into the association between outlet density and alcohol-related harms has been ongoing since the 1970s (e.g. 12, 13). In the last two decades, the quality of studies has improved with use of smaller geographical units, inclusion of more socio-demographic controlling variables, and more sophisticated methods of statistical analysis $(14,15)$. In general, the literature indicates that greater outlet density is associated with greater levels of problems, although associations have varied by outlet type (on-premises outlets, which primarily sell alcohol for on-site consumption, and offpremises outlets, which sell alcohol for consumption off-site) and outcome measured (16).

Likewise, the impact of changes to trading hours has been the subject of investigation for many years and the literature demonstrates that an increase in trading hours at on-premises outlets is associated with increased alcohol consumption and harms (17). Previous research in Perth, Australia, demonstrated that rates of assault and road crashes increased significantly over time following the introduction of extended trading hours at hotels/taverns (one to two additional hours after midnight) $(18,19)$. More recent research from Norway suggests that a one hour increase in trading hours on weekend nights affects a $20 \%$ increase in violent crime in city centres (20). Other recent studies from 
Russia, Brazil, the Netherlands and the USA concur that there is a link between extended trading hours, increased alcohol consumption (21), injuries (22) and violent crime $(23,24)$.

Recent studies have explored associations between minimum pricing and consumption (25), alcoholrelated morbidity (26) and mortality (27). However, the association between total sales and alcoholrelated harm has received considerably less attention in the literature; exceptions include three crosssectional studies (28-30). Alcohol sales may account for variations (e.g. in size) among outlets in relation to their capacity to influence levels of alcohol consumption within a community (30). In most countries, the absence of routine sales data collection at outlet-level precludes estimating the effects of outlet density and type of outlet on consumption in populations of interest. Both Australian studies mentioned above $(28,30)$ suggested that, independent of outlet density, alcohol sales were associated with violence. The Western Australian study found that counts of on- and sales per off-premises outlets were significantly positively associated with violence (30).

The main aim of this study was to test the effects of licensed outlets, trading hours and alcohol sales on levels of alcohol-related injuries presenting at Perth metropolitan Emergency Departments (EDs), using a panel study design. It was hypothesised that the association between alcohol-related injury and both counts of outlets and sales at these outlets would vary between on- and off-premises outlets, and that the associations would be of a larger magnitude at on-premises outlets with extended trading hours.

\section{Methods}

The study was a retrospective population-based study using panel data from 1 July 2002 to 30 June 2010 in the Perth metropolitan area in Australia. Perth, the capital city of the state of Western Australia (WA), is located on the south-western coast of the state, and is socio-economically and demographically comparable to other Australian capital cities (31). As of the 2011 national census, the population of the Greater Perth Area was 1,728,867 residents. 
The Perth metropolitan area was defined as the Perth Statistical Division (SD) of WA (32). The 117 postcodes used in the analysis were those specified in the Australian Bureau of Statistics (ABS) postal area concordances for the Perth SD for 2006 (33). Postal area boundaries within the metropolitan area were found to be relatively stable over time, with changes of less than 5\% of total area when published ABS postal area digital boundaries for 2001, 2006 and 2011 were compared $(34,35)$.

\section{Alcohol-related injuries}

The Emergency Department Information System (EDIS) collates ED presentations for the nine public hospitals located in the Perth metropolitan area with EDs. ED data was obtained from the Western Australian Data Linkage Branch (WADLB). The data collection is only available from 2002 and was requested up to the latest available year. The EDIS did not include records for the one private ED in Perth, accounting for approximately $5 \%$ of ED presentations (36). In keeping with WADLB privacy policy, place of residence of ED presentations was indicated by postcode only. Data on 1,796,949 deidentified ED presentations were provided, including principal diagnosis (ICD-10), age, sex, Indigenous status, date and time of day of presentation, postcode of residence and SEIFA (Socioeconomic Index for Areas). Because Perth EDs do not reliably or consistently record blood alcohol levels or external cause codes, a surrogate measure of ED alcohol-related injury was applied. The use of surrogate methodology is well described in the literature (37-39). Presenting day of week and time of day data were used to identify cases that are likely to be alcohol-related; these data fields typically have high reliability and completion rate. Using the methods described by Young et al. $(39,40)$ and Evans et al. (41), the surrogate measure was validated specifically for Perth EDs using known wholly alcohol-involved cases and all injury cases. Wholly alcohol-involved cases were identified by the following ICD-10 codes: F10 (mental disorders related to alcohol use); K85.2 (alcohol-induced acute pancreatitis); T51 (toxic effect of alcohol); X45, X65 and Y15 (poisoning by alcohol); R78.0, Y90, Y91 and Z04.0 (evidence of alcohol involvement from blood alcohol level or degree of intoxication); and Z72.1 (alcohol use) (41). Injury cases were defined as having ICD-10 codes between S00.0 and T98.3 (42) and included conditions such as fractures, traumatic brain injuries, burns and poisonings. 
The day and time of presentation was available for all ED presentations. Two time-based surrogate measures were identified: (i) 'Night' presentations for injuries which occurred between midnight and 5am Monday to Sunday; and (ii) 'Weekend night' injuries which occurred in the same time period on Saturday, Sunday and Monday. The Weekend night surrogate indicated higher specificity but with a smaller number of cases than the Night surrogate measure: further details can be found in Evans et al. (41) and Young et al.(40). Of 485,501 injuries, 30,682 (6.3\%) were Weekend night injuries and $51,241(10.6 \%)$ were Night injuries (Table 1).

[Table 1 here]

\section{Licensed outlets}

The Drug and Alcohol Office (DAO) of Western Australia provided data on licensed outlets operating in the region during the study period including: trading name, type of licence (i.e. liquor store, hotel/tavern, nightclub, community club, restaurant or other) and postcode. Beverage-specific volumes of alcohol purchased by licensees from wholesalers in each financial year were also provided at postcode-level. These 'alcohol sales' data are considered a quality indicator of population-level consumption (37) and the WA sales data are particularly reliable (43, 44). Alcohol volumes were converted to pure alcohol using conversion factors specific to each beverage type $(45,46)$.

Data on which outlets possessed Extended Trading Permits (ETPs), authorising extended trading hours, were obtained from a combination of sources including the DAO (2006-2010) and archived records from the WA Department of Racing, Gaming and Liquor (1990-1998). No data were available for the years 1999-2005. However, since ETPs continue for the life of the liquor licence (18), a list of outlets with ETPs was compiled for the full study period using the start and end dates of ETPs in the available records. Most ETPs allowed an extension of trading hours for one to two hours past midnight from Monday to Saturdays or past 10pm on Sundays. The proportion of off-premises outlets (liquor stores) with extended trading hours was negligible (less than 1\%). Therefore, trading hours distinctions were only made for on-premises outlets (i.e. hotel/tavern, nightclub, community club, 
restaurant or other). There were 65 (3.7\%) on-premises outlets with extended trading hours, 1,678 (96\%) on-premises outlet with standard trading hours, and 318 off-premises outlets in 2009/10.

\section{Demographic and socio-economic factors of postcodes}

Postcode-level demographic and socio-economic data were obtained from the Australian Bureau of Statistics (ABS) for the 2001, 2006 and 2011 censuses. Using the data from the census years, the values for the missing years were calculated, using the 'ipolate' command in Stata to perform linear interpolation (47). Demographic variables included: estimated resident population over 15 years; ratio of male to female residents; proportion of young (15 to 24 year old) male residents; mean age; ratio of Indigenous to non-Indigenous residents; and ratio of unemployed to employed residents (Table 2). Postcode-level socio-economic status was measured using the SEIFA Index of Relative SocioEconomic Advantage and Disadvantage, an index developed by the ABS using census data including data on income, education, and internet access of residents of each postcode $(48,49)$.

[Table 2 here]

\section{Other postcode-level variables}

It was anticipated that the prevalence of injury and associations between alcohol availability and alcohol-related injury in postcodes close to the Central Business District (CBD) would differ from postcodes further from the CBD due to differences in the road networks, congestion levels and travel patterns. Postcodes closer to the CBD are smaller than outer postcodes (50). A framework proposed by Luk and colleagues (51) was adopted to account for differences in injury prevalence across the city. The framework divided the Perth metropolitan area into four area categories based on the distance between a pair of traffic signals (a road link): i) CBD: road links were approximately 300m (or less); ii) Inner suburbs: road links between $300 \mathrm{~m}$ and $1,000 \mathrm{~m}$ (within $7 \mathrm{~km}$ of the city centre but outside the CBD); iii) Middle suburbs: road links between 1,000m and $1.5 \mathrm{~km}$ (between $7 \mathrm{~km}$ and 
$15 \mathrm{~km}$ of the CBD); and iv) Outer suburbs: road links greater than $1.5 \mathrm{~km}$ (beyond $15 \mathrm{~km}$ from the CBD). Each Perth postcode was allocated to one of these four zones.

\section{Analysis}

Alcohol-related injury, alcohol availability (outlet counts with their trading hours and sales) and other postcode-level data were merged and aggregated to postcode and financial year. The correlations between each variable are indicated in Supplementary Table 1. The data had a panel structure: financial year was the time variable ( $\mathrm{n}=8)$ and postcode was the panel ID (cross-sectional) variable $(\mathrm{n}=117)$ in the models, giving 936 data points. The relationship between alcohol availability and alcohol-related injury was modelled using negative binomial regression with random effects because of the low number of alcohol-related injuries presenting at EDs and the probable over-dispersion of the data. The random effects accounted for the 'clustering' of the data by postcode and financial year (52). Stata 12 was used for the statistical analysis (47).

The outcome variables were Night injuries and Weekend night injuries. The statistical models were repeated for each of these surrogate measures of alcohol-related injury. Six measures of alcohol availability were used in the models: counts of on-premises outlets with standard trading hours and extended trading hours; counts of off-premises outlets; sales per on-premises outlet with standard trading hours and extended trading hours; and sales per off-premises outlet. Counts of outlets were used in preference to outlet density (30), with models incorporating estimated resident population as an exposure variable rather than a denominator of density. Sales per outlet (mean sales) were used instead of absolute volume of sales in the postcode, because of much lower correlations between the sales per outlet and counts of outlets (Supplementary Table 2). Socio-economic and demographic variables (indicated in Table 2) were included in the final models, as well as the categorical variable, zone from the Perth CBD. The residuals of the models were tested for spatial autocorrelation using Global Moran's I. Values ranged from 0.026 to 0.082 (across years and outcome measures), indicating no statistically significant spatial autocorrelation (at alpha $=0.05$ ). 


\section{Results}

Table 1 presents the descriptive statistics and injury subgroups for the time-based surrogates of alcohol-related injury. Descriptive statistics relating to independent variables are presented in Table 2.

Raw incidence rates for alcohol-related injury were developed for each zone from the CBD and for a postcode with mean counts and sales per outlet (Supplementary Table 3). Incidence rates were highest in the CBD (78,278 Night injuries per 10,000 population) and in 2008/9 (58,499 Night injuries per 10,000 population).

Simple negative binomial models with random effects were developed for each of the alcohol availability variables. Counts of on-premises outlets (with both standard and extended trading hours) and sales per off-premises outlet were positively significantly associated with alcohol-related injury in preliminary analyses (Supplementary Tables 4-9).

Final models included all postcode-level variables. Model results for each of the two alcohol-related injury surrogate measures are presented in Table 3. At postcode-level, each additional on-premises outlet with extended trading hours was associated with a $4.6 \%$ increase in Night injuries and a $4.9 \%$ increase in Weekend night injuries. An additional on-premises outlet with standard trading hours was associated with a $0.6 \%$ increase in Night injuries and $0.8 \%$ increase in Weekend night injuries. An increase of 10 kilolitres $(\mathrm{kL})$ sold per off-premises outlet increased risk of injury by $1.9 \%$ for both outcomes variables. Conversely, counts of off-premises outlets were negatively associated with alcohol-related injury indicating a 3.9\% to $4.9 \%$ lower risk per additional outlet. However, the apparent protective effect associated with greater numbers of outlets was outweighed by the increased risk of injury associated with greater sales: standardising to litres sold, for a postcode with average off-premises outlet sales and an average number of off-premises outlets $(67,1161$ and 2.6 outlets respectively - Table 2), the overall effect was to increase the absolute number of Night and Weekend night injuries by about $5 \%$ per additional 10kL of alcohol sold. 
When outlet counts and sales were controlled for, postcodes with a higher proportion of residents of Indigenous origin (IRR: 1.291) and postcodes in the highest SEIFA quartile (indicating higher socioeconomic status - IRR: 1.370) had an increased risk of Night injuries. The associations were similar for Weekend night injury. There was a 33.9\% increase in risk of Night injury in the postcodes between the $\mathrm{CBD}$ and $7 \mathrm{~km}$ from the $\mathrm{CBD}$, compared to postcodes situated more than $15 \mathrm{~km}$ from the Perth CBD. The risk of both measures of alcohol-related injury was lower in postcodes with a higher proportion of unemployed people, males and young males.

[Table 3 here]

\section{Discussion}

Night and Weekend night alcohol-related injuries were associated with both on- and off-premises outlets. The direction and strength of the association depended, however, on outlet type, whether counts or sales were applied and whether extended trading hours were present.

\section{Off-premises outlets}

Higher alcohol sales among off-premises outlets were associated with increased risk of alcoholrelated injury. This association may be due to the effect that off-outlets have on economic availability or 'affordability' $(30,53)$. Larger outlets (often warehouse-style chain stores), with greater capacity, are able to offer sizeable discounts and other incentives, enabling drinkers to purchase more alcohol for the same price, such that the 'real price' of alcohol falls and the economic availability (54) of alcohol increases. Conversely, greater numbers of off-premises outlets appeared to reduce injury risk. This unexpected finding may be partly due to liquor outlets being situated closer to drinker residences (or workplaces) thereby reducing travel time to and from outlets and lowering risk of transport injury. Alternatively, the closer proximity of off-premises outlets may reduce the number of occasions that drinkers frequent on-premises outlets; that is, readily available low-cost alcohol may encourage drinking in the home rather than at hotels where alcohol is more expensive. 


\section{On-premises outlets}

Consistent with earlier findings on outlets and police-reported violent assault in Western Australia (30), this study found that counts of outlets were significantly associated with alcohol-related ED injury but alcohol sales per outlet were not. This suggests that, for on-premises outlets, mere physical presence and associated situational factors may be more important predictors of injury risk than the amount of alcohol they sell. Livingston and colleagues discuss two mechanisms by which outlet density may influence alcohol-related harm: the proximity effect, "how easily one can access alcohol", and the amenity effect, "the negative effects... of licenced premises on the neighbourhoods in which they operate" (53, p. 561). For example, by creating an 'entertainment district' that draws in large numbers of drinkers, clusters of outlets may produce a combined effect that is larger than the sum of effects from individual outlets. These outlet clusters act as "attractors of trouble" (53, p. 561) and facilitate large crowds of intoxicated people walking on the streets and moving between outlets. Liang and Chikritzhs suggested that, unlike drinkers who purchase from off-premises outlets, onpremises drinkers remain at venues for extended periods, becoming more intoxicated over the course of the evening and thereby increasing the likelihood of violence (30).

A unique feature of this study was the analysis of independent associations between both alcohol sales and counts of outlets by trading hours (standard vs. extended), and alcohol-related injury. Compared to an additional on-premises outlet with standard trading hours, the risk of alcohol-related injury associated with venues operating with extended trading hours was substantially larger. This is consistent with research by Chikritzhs and Stockwell $(18,55)$ which showed that late trading hotels had significantly higher levels of violence and associated road crash injury. Thus, higher densities of on-premises outlets trading with extended hours present a particularly high risk of injury. 


\section{Limitations}

The harm data used in this study were official ED presentation records. While the quality of these data is typically high for key fields (e.g. date and time of day), the documentation of external causes of injury (which would assist in the identification of potential alcohol-related cases) are rarely available in Australian ED records (56). This study therefore relied on time-based surrogate measures to identify alcohol-related injuries. As a result, some cases classified as 'alcohol-related' may not have involved alcohol consumption and other cases which did involve alcohol may have been excluded. However, previous research has shown that surrogate measures of alcohol-involvement are a reliable means of measuring trends over time (38). Moreover, the surrogate measure used in this study was validated specifically for Perth EDs, using an established validation method $(39,41,57)$.

A limitation of using ED records is that location information is restricted to the patient's place of residence, and data on last place of drinking is not recorded. Thus, it was not possible to link alcoholrelated presentations with a specific outlet or a particular type of outlet.

As comprehensive records of trading hours for the first three years of the study were not available, these had to be interpolated using the previous and following years. Although unlikely, some minor coding errors may have been incurred in this process. Further, due to small numbers of cases, trading hours were grouped as either extended or standard; i.e., on-premises outlets were not distinguished according to whether the extended trading hours affected each day of the week or were limited to weekend nights only.

\section{Implications}

These findings provide further evidence to support limiting the granting of liquor licences and extended trading hours to reduce alcohol-related harm. They also indicate that the granting of on- and off-premises outlet licences may require different management strategies in order to reduce alcoholrelated harms. 
The use of licence conditions to limit the size and capacity of off-premises outlets, rather than merely controlling the number of off-premises licences, may be important for regulating retail prices and economic availability. Limiting, for instance, the number of licences which are granted to large warehouse-style outlets with substantial discounting capacity, should be considered. The price of alcohol is a significant and modifiable determinant of consumer purchasing behaviour (58). Limiting the minimum price at which alcohol can be sold and increasing the average price (per standard drink) of alcoholic beverages may counter some of the discounting strategies employed by off-premises outlets which aim to increase volume of sales (59). Further research into off-premises outlets with very high levels of sales is warranted.

The association between on-premises outlets and injury appears to be underpinned by the physical presence of the outlets rather than their capacity to influence alcohol sales. Decisions relating to limits in the number of on-premises outlets should consider not only the total number of licences in a given area, but also the relative geographic position of outlets to each other. Perhaps more importantly, however, is the need for licensing decision-makers to consider the merits of reducing the number of on-premises outlets operating with extended operating hours. Previous studies have demonstrated a strong association between extended trading hours and harm $(17,18,20,55)$ and have also indicated that a reduction in trading hours can reduce harms (60). In this study, although on-premises outlets with standard trading hours were associated with increased injury risk, the effect associated with their late trading counterparts was nearly eight times greater.

\section{Conclusion}

This research provides evidence of associations between alcohol-related injury and the number of alcohol outlets, sales per outlet, and trading hours. The associations between on- and off-premises outlets and injury appear to be underpinned by different mechanisms and will require tailored policy in order to reduce alcohol-related harms. On-premises outlets with extended trading hours present a specific challenge in addressing alcohol-related injury. 


\section{Acknowledgements:}

Thank you to William Gilmore at the National Drug Research Institute for his helpful comments on the manuscript.

\section{References}

1. CHERPITEL, C. J. (1993) Alcohol and injuries: a review of international Emergency Room studies, Addiction, 88, 923-937.

2. CHERPITEL, C. J. (2007) Alcohol and injuries: a review of international Emergency Room studies since 1995, Drug and Alcohol Review, 26, 201-214.

3. NORSTRÖM, T. (2000) Outlet density and criminal violence in Norway, 1960-1995, Journal of Studies on Alcohol, 61, 907-911.

4. GRUENEWALD, P. J. \& REMER, L. (2006) Changes in outlet densities affect violence rates, Alcoholism: Clinical and Experimental Research, 30, 1184-1193.

5. CUNRADI, C. B., MAIR, C., PONICKI, W. \& REMER, L. (2012) Alcohol outlet density and intimate partner violence-related Emergency Department visits, Alcoholism: Clinical and Experimental Research.

6. LIVINGSTON, M. (2011) A longitudinal analysis of alcohol outlet density and domestic violence, Addiction, 106, 919-925.

7. SCRIBNER, R. A., MACKINNON, D. P. \& DWYER, J. H. (1994) Alcohol outlet density and motor vehicle crashes in Los Angeles County cities, Journal of Studies on Alcohol, 55, 447-453.

8. TReno, A. J., Johnson, F. W., Remer, L. \& GRUeneWALD, P. (2007) The impact of outlet densities on alcohol-related crashes: a spatial panel approach, Accident Analysis and Prevention, 39, 894-901.

9. Freisthler, B., Needell, B. \& GRUenewald, P. J. (2005) Is the physical availability of alcohol and illicit drugs related to neighborhood rates of child maltreatment?, Child Abuse and Neglect, 29, 1049-1060.

10. MAIMON, D. \& BRoWNING, C. R. (2012) Underage drinking, alcohol sales and collective efficacy: Informal control and opportunity in the study of alcohol use, Social Science Research.

11. Paschall, M. J., Grube, J. W., Thomas, S., CAnNon, C. \& Treffers, R. (2012) Relationships between local enforcement, alcohol availability, drinking norms, and adolescent alcohol use in 50 California cities, Journal of Studies on Alcohol and Drugs, 73, 657.

12. SMART, R. G. \& DOCHERTY, D. (1976) Effects of introduction of on-premise drinking on alcoholrelated accidents and impaired driving, Journal of Studies on Alcohol, 37, 683-686.

13. PARKER, D. A. \& HARMAN, M. S. (1978) The distribution of consumption model of prevention of alcohol problems. A critical assessment, Journal of Studies on Alcohol, 39, 377-399.

14. TOOMEY, T. L., ERICKSON, D. J., CARLIN, B. P. et al. (2012) The association between density of alcohol establishments and violent crime within urban neighborhoods, Alcoholism: Clinical and Experimental Research.

15. PONICKI, W. R., GRUENEWALD, P. J. \& REMER, L. G. (2013) Spatial panel analyses of alcohol outlets and motor vehicle crashes in California: 1999-2008, Accident Analysis and Prevention, 55, 135-143.

16. BABOR, T., CAETANO, R., CASSWELL, S. et al. (2010) Regulating the physical availability of alcohol Alcohol: No Ordinary Commodity, pp. 127-146 (Oxford, Oxford University Press). 
17. STOCKWELL, T. \& CHIKRITZHS, T. (2009) Do relaxed trading hours for bars and clubs mean more relaxed drinking? A review of international research on the impacts of changes to permitted hours of drinking, Crime Prevention and Community Safety, 11, 153-170.

18. CHIKRITZHS, T. \& STOCKWELL, T. (2002) The impact of later trading hours for Australian public houses (hotels) on levels of violence, Journal of Studies on Alcohol, 63, 591.

19. CHIKRITZHS, T. N. (2004) The impact of extended trading hours in licensed premises on indicators of alcohol-related harm National Drug Research Institute, pp. 297 (Perth, Curtin University of Technology).

20. ROSSOW, I. \& NORSTRÖM, T. (2012) The impact of small changes in bar closing hours on violence. The Norwegian experience from 18 cities, Addiction, 107, 530-537.

21. KOLOSNITSYNA, M., SITDIKOV, M. \& KHORKINA, N. (2014) Availability restrictions and alcohol consumption: A case of restricted hours of alcohol sales in Russian regions, 2014, 3, 9.

22. DE GoEIJ, M. C. M., VeldhUIZEN, E. M., BUSTER, M. C. A. \& KUnST, A. E. (2015) The impact of extended closing times of alcohol outlets on alcohol-related injuries in the nightlife areas of Amsterdam: a controlled before-and-after evaluation, Addiction, n/a-n/a.

23. SÁNCHEZ, Á. I., VILLAVECES, A., KRAFTY, R. T. et al. (2011) Policies for alcohol restriction and their association with interpersonal violence: a time-series analysis of homicides in Cali, Colombia, International Journal of Epidemiology, 40, 1037-1046.

24. SCHOFIELD, T. P. \& DENSON, T. F. (2013) Alcohol Outlet Business Hours and Violent Crime in New York State, Alcohol and Alcoholism, 48, 363-369.

25. STOCKWELL, T., AULD, M. C., ZHAO, J. H. \& MARTIN, G. (2012) Does minimum pricing reduce alcohol consumption? The experience of a Canadian province, Addiction, 107, 912-920.

26. StOCKWELL, T., ZHAO, J., MARTIN, G. et al. (2013) Minimum Alcohol Prices and Outlet Densities in British Columbia, Canada: Estimated Impacts on Alcohol-Attributable Hospital Admissions, American Journal of Public Health, 103, 2014-2020.

27. ZHAO, J., STOCKWELL, T., MARTIN, G. et al. (2013) The relationship between minimum alcohol prices, outlet densities and alcohol-attributable deaths in British Columbia, 2002-09, Addiction, 108, 1059-1069.

28. StEVENSON, R. J., LIND, B. \& WeATHERBURN, D. (1999) Property damage and public disorder: their relationship with sales of alcohol in New South Wales, Australia, Drug and Alcohol Dependence, 54, 163-170.

29. RAY, J. G., MOINEDDIN, R., BELL, C. M. et al. (2008) Alcohol sales and risk of serious assault, PLoS Medicine, 5, e104.

30. LIANG, W. \& CHIKRITZHS, T. (2011) Revealing the link between licensed outlets and violence: counting venues versus measuring alcohol availability, Drug and Alcohol Review, 30, 524535 .

31. ABS (2014) 3218.0 - Regional Population Growth, Australia, 2012-13.

32. ABS (2009) Australian Standard Geographical Classification (ASGC): Western Australia maps (Commonwealth of Australia).

33. ABS (2007) 2905.0.55.001 - ABS Postal Area Concordances: August 2006.

34. ABS (2007) 2923.0.30.001 - Census of Population and Housing: Census Geographic Areas Digital Boundaries, Australia, 2006

35. ABS (2006) 1216.0 - Statistical Geography Volume 1 - Australian Standard Geographical Classification (ASGC).

36. HolmAN, C. D. J. (2009) Attendances at Perth Metropolitan Hospital Emergency Departments attributable to tobacco in 2008, in: Daube, M. (Ed.).

37. STOCKWELL, T. \& CHIKRITZHS, T. (2000) International Guide for Monitoring Alcohol Consumption and Related Harm (Department of Mental Health and Substance Dependence, Noncommunicable Diseases and Mental Health Cluster, World Health Organization). 
38. BRINKMAN, S., CHIKRITZHS, T., StockWeLL, T. \& MATHEWSON, P. (2001) An indicator approach to the measurement of alcohol-related violence, in: Williams, P. (Ed.) Alcohol, young persons and violence, pp. 61-84 (Canberra, Australian Institute of Criminology).

39. Young, D. J., STOCKWELL, T., CHERPITEL, C. et al. (2004) Emergency Room injury presentations as an indicator of alcohol-related problems in the community: a multilevel analysis of an international study, Journal of Studies on Alcohol, 65, 605-612.

40. YOUNG, D. J., STOCKWELL, T. R., CHERPITEL, D. J. et al. (2004) Emergency Room injury presentations as a surrogate measure of alcohol-related problems in the community: a multilevel analysis of an international study (Perth, Australia, National Drug Research Institute, Curtin University of Technology).

41. EVANS, M., PASCAL, R. \& CHIKRITZHS, T. (2011) South Australian Emergency Department presentations as indicators of alcohol-related harm: feasibility study. Stage 2: final report (National Drug Research Institute).

42. WORLD HEALTH ORGANISATION ICD-10 Version 2007.

43. The MEASUREMENT OF ALCOHOL PROBLEMS FOR Policy (1995) A first report of research in progress (Perth, WA, National Centre for Research into the Prevention of Drug Abuse, Curtin University).

44. CATAlANO, P., ChiKRItZHS, T., StockWell, T. et al. (2001) Trends in per capita alcohol consumption in Australia, 1990/91-1998/99. (Perth, WA, National Drug Research Institute Monograph no. 4).

45. CHIKRITZHS, T., AlLSOP, S., Moodie, A. R. \& HALL, W. D. (2010) Per capita alcohol consumption in Australia: will the real trend please step forward?, Medical Journal of Australia, 193, 1-4.

46. LOXLEY, W., CHIKRITZHS, T. \& CATALANO, P. (2011) National Alcohol Sales Data Project stage two: final report (Perth, Western Australia, National Drug Research Institute, Curtin University of Technology).

47. STATACORP (2011) Stata Statistical Software: release 12 (College Station, TX, StataCorp LP.).

48. ABS (2001) 2033.0.55.001 - Census of Population and Housing: Socio-Economic Indexes for Areas (SEIFA), Australia, 2001

49. ABS (2008) 2033.0.55.001 - Census of Population and Housing: Socio-Economic Indexes for Areas (SEIFA), Australia , 2006.

50. ABS (2006) Postal Areas (POA) 2006 Digital Boundaries in ESRI Shapefile Format 2923.0.30.001 - Census of Population and Housing: Census Geographic Areas Digital Boundaries, Australia, 2006.

51. LUK, J., LLOYD, B. \& YOO, Y. (2009) New speed-flow curves for Perth, pp. 52 (Vermont South, ARRB Group Ltd).

52. KIRKWOOD, B. R. \& STERNE, J. A. C. (2003) Essential Medical Statistics (Blackwell Science).

53. LIVINGSTON, M., CHIKRITZHS, T. \& ROOM, R. (2007) Changing the density of alcohol outlets to reduce alcohol-related problems, Drug and Alcohol Review, 26, 557-566.

54. SMART, R. G. (1980) Availability and the prevention of alcohol-related problems, in: Harford, T. C., Parker, D. A. \& Lights, L. (Eds.) Normative Approaches to the Prevention of Alcohol Abuse and Alcoholism, pp. 123-146 (Washington, DC, U.S. Government Printing Office).

55. CHIKRITZHS, T. \& STOCKWELL, T. (2006) The impact of later trading hours for hotels on levels of impaired driver road crashes and driver breath alcohol levels, Addiction, 101, 1254-1264.

56. CHIKRITZHS, T., EVANS, M., GARDNER, C. et al. (2011) Australian alcohol aetiologic fractions for injuries treated in Emergency Departments (Perth, National Drug Research Institute, Curtin University).

57. HoBdAY, M. B. (2014) The Effect of Alcohol Outlets and Sales on Alcohol-Related Injuries Presenting at Emergency Departments in Perth, Australia, from 2002 to 2010 National Drug Research Institute, pp. 448 (Perth, Australia, Curtin University). 
58. BABOR, T., CAETANO, R., CASSWELL, S. et al. (2010) Controlling affordability: pricing and taxation Alcohol: No Ordinary Commodity, pp. 109-125 (Oxford, Oxford University Press).

59. PuRshouse, R. C., Meier, P. S., Brennan, A., TAYLOR, K. B. \& RAFIA, R. (2010) Estimated effect of alcohol pricing policies on health and health economic outcomes in England: an epidemiological model, The Lancet, 375, 1355-1364.

60. KYPRI, K., MCELDUfF, P. \& MILLER, P. (2014) Restrictions in pub closing times and lockouts in Newcastle, Australia five years on, Drug and Alcohol Review, 33, 323-326. 
Table 1: Descriptive statistics for Night and Weekend night injuries presenting at Perth metropolitan Emergency Departments from 1 July 2002 to 30 June 2010

\begin{tabular}{lllll}
\hline Injury cases & \multicolumn{2}{c}{ Night $^{1}$} & \multicolumn{2}{c}{ Weekend night $^{2}$} \\
& $\mathrm{n}$ & $\%$ & $\mathrm{n}$ & $\%$ \\
\hline Male & 33,651 & 65.67 & 20,747 & 67.62 \\
Female & 17,590 & 34.33 & 9,935 & 32.38 \\
Young males (15-24 years) & 14,819 & 28.92 & 10,389 & 33.86 \\
Indigenous & 3,074 & 6 & 1,500 & 4.89 \\
Not Indigenous & 44,549 & 86.94 & 26,823 & 87.42 \\
Unknown Indigenous status & 3,618 & 7.06 & 2,359 & 7.69 \\
Toxic effects of alcohol (T51) & 975 & 1.90 & 698 & 2.27 \\
Injury (ICD-10 codes: S00-T14) & 42,349 & 82.65 & 26,032 & 84.84 \\
Poisoning (ICD-10 codes: T15-T98 & 8,260 & 16.12 & 4,273 & 13.93 \\
Other (ICD-10 codes: W27, W59, Y07) & 632 & 1.23 & 377 & 1.23 \\
\hline Total cases & 51,241 & 100 & 30,682 & 100 \\
\hline
\end{tabular}

${ }^{1}$ Night: Midnight to 4:59am, daily

${ }^{2}$ Weekend night: Midnight to 4:59am, on Saturday, Sunday and Monday morning

Table 2: Alcohol availability, socio-economic and demographic variables from the ABS with descriptive statistics at postcode-level in Perth metropolitan area, from 1 July 2002 to 30 June 2010

\begin{tabular}{|c|c|c|c|c|}
\hline & Mean & Standard Deviation & Minimum & Maximum \\
\hline \multicolumn{5}{|l|}{ Counts of alcohol outlets per postcode } \\
\hline Count of all on-premises outlets with an ETP & 0.51 & 1.53 & 0.00 & 14.00 \\
\hline $\begin{array}{l}\text { Count of all on-premises outlets with standard trading } \\
\text { hours }\end{array}$ & 10.54 & 17.24 & 0.00 & 174.00 \\
\hline Count of off-premises outlets (liquor stores) & 2.60 & 2.10 & 0.00 & 13.00 \\
\hline \multicolumn{5}{|l|}{ Total volume of alcohol sales (litres pure alcohol) } \\
\hline Total on-premises sales with an ETP & 7,089 & 19,557 & 0 & 144,472 \\
\hline Total on-premises sales with standard trading hours & 40,469 & 51,788 & 0 & 566,280 \\
\hline Total off-premises sales & 67,116 & 80,079 & 0 & 618,060 \\
\hline \multicolumn{5}{|l|}{ Socio-economic and demographic variables } \\
\hline Total population over 15 (ERP) & 10,443 & 8,879 & 1 & 42,040 \\
\hline SEIFA index of advantage/disadvantage (quartiles) & 1,037 & 63 & 889 & 1,207 \\
\hline Mean age & 36 & 2.3 & 31 & 61 \\
\hline Ratio of Indigenous to non-Indigenous residents (x 100) & 2.70 & 12 & 0 & 145 \\
\hline Ratio of males aged $15-24$ to total population (x100) & 7.3 & 1.8 & 0 & 15 \\
\hline Ratio of males to females (x100) & 101 & 35 & 0 & 380 \\
\hline Ratio of unemployed to employed residents (x100) & 5.2 & 3.5 & 0 & 56 \\
\hline
\end{tabular}


Table 3: Panel models predicting injuries for counts and sales of on- and off-premises outlets, including trading hours, adjusting for demographic and socio-economic status, and distance from the CBD, in Perth metropolitan area between 1 July 2002 and 30 June 2010

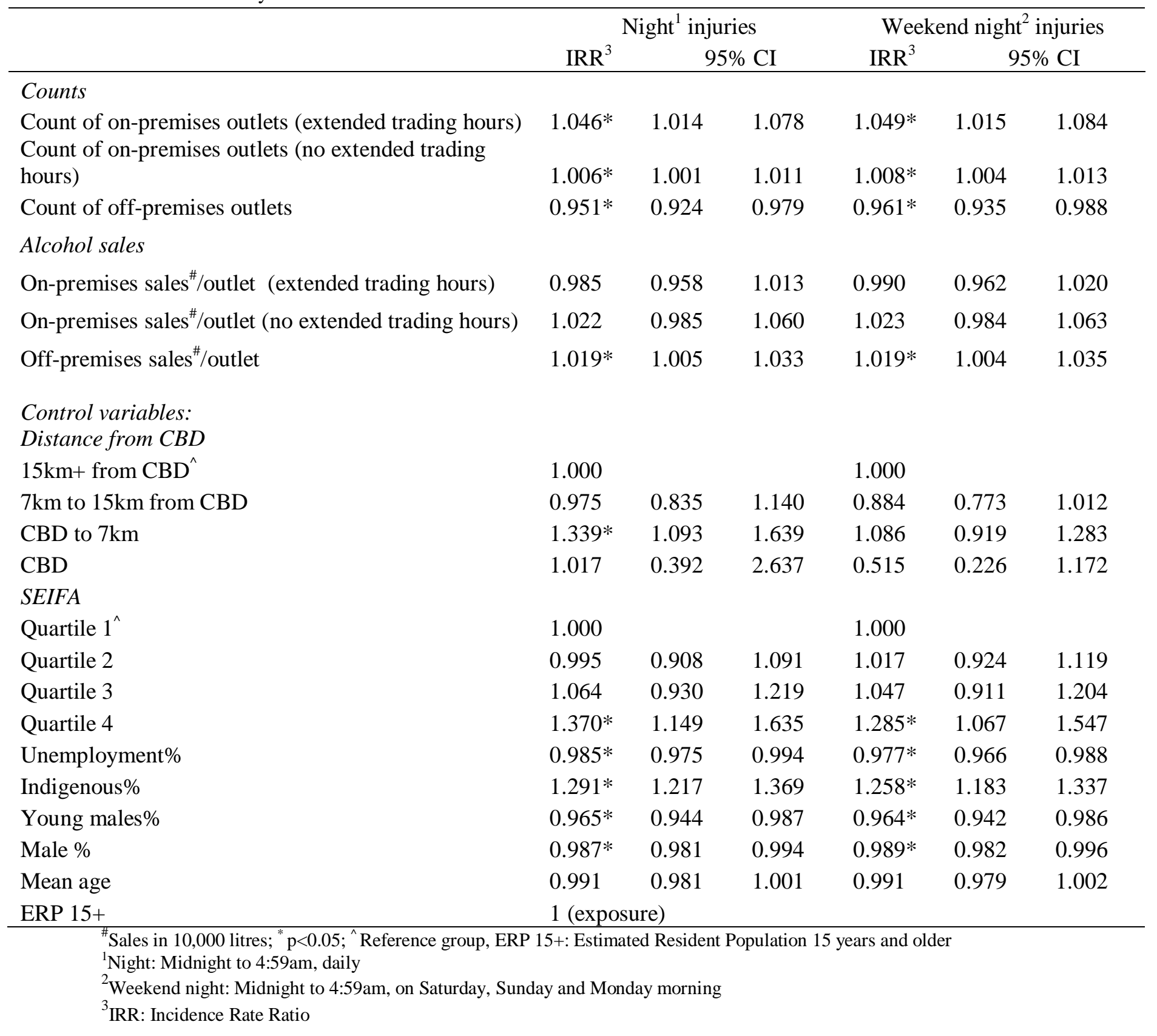

